\title{
Clinical issues of mucus accumulation in COPD
}

This article was published in the following Dove Press journal:

International Journal of COPD

25 March 2014

Number of times this article has been viewed

\section{Christian R Osadnik ${ }^{1,2}$ Christine F McDonald 2,3 Anne E Holland ${ }^{2,4,5}$}

'Department of Physiotherapy, Monash University, ${ }^{2}$ Institute for Breathing and Sleep, Austin Health, ${ }^{3}$ Department of Respiratory and Sleep Medicine, Austin Health, ${ }^{4}$ Department of Physiotherapy, La Trobe University, ${ }^{5}$ Department of Physiotherapy, Alfred Health, Melbourne, VIC, Australia
Correspondence: Christian R Osadnik Department of Physiotherapy,

Monash University, Peninsula Campus, McMahons Road, Frankston,

Victoria 3199, Australia

\section{Dear editor}

We wish to thank Ramos et al for presenting a succinct and up-to-date synthesis of the evidence relating to the important issue of mucus hypersecretion in COPD. ${ }^{1}$ The authors highlight the association of mucus hypersecretion with poor outcomes, including increased risk of exacerbations, hospitalization and mortality. These associations have led to interest in the potential benefits of mucus clearance techniques in COPD. As Ramos et al ${ }^{1}$ point out, although the physiological rationale for airway clearance techniques (ACTs) in COPD is strong, clinical efficacy has historically been difficult to establish, perhaps due to the variety of techniques and outcomes that have been employed in small studies. We have recently synthesized this body of evidence in a Cochrane systematic review of ACTs for individuals with COPD. The review demonstrated ACTs are safe and meta-analysis showed they confer small beneficial effects on a limited range of important clinical outcomes, such as the need for and duration of ventilatory assistance during an acute exacerbation of COPD (AECOPD). ${ }^{2}$

We agree with Ramos et $\mathrm{al}^{1}$ that ACTs based upon positive expiratory pressure (or PEP) appear to be physiologically suited to addressing the underlying pathophysiology and mechanics of the lungs in individuals affected by COPD. This is supported by non-significant trends of improved efficacy of PEP-based ACTs over other types of ACTs, ${ }^{2}$ and was the premise of our multicentre, randomized controlled trial ( $\left.\mathrm{n}=92\right)$ investigating the effect of PEP compared to usual care consisting of no ACTs in patients with AECOPD. ${ }^{3}$ However, this study demonstrated a clear lack of benefit in a range of important clinical outcomes, including self-reported symptom severity, both in the short-term and long-term. The lack of impact of ACTs on significant outcomes in COPD is now emerging consistently in the literature, such as the important investigation by Cross et $\mathrm{al}^{4}$ of manual chest physical therapy (percussions and vibrations) in 526 inpatients with AECOPD.

A theme of these new investigations is the importance of outcome choice. Much of the existing literature in the area of ACTs in COPD is founded on outcomes such as forced expiratory volume or measures of sputum clearance. These may be intuitively useful and relatively simple to obtain, however measures of lung function correlate poorly with more relevant patient-centered outcomes ${ }^{5}$ and measures of sputum clearance are fraught with limitations regarding their interpretation. Both are no longer considered useful indicators of ACT success. ${ }^{6}$ Future investigations in this area should address whether ACTs can modify 
the important adverse outcomes associated with mucus hypersecretion, as outlined in the review of Ramos et al. ${ }^{1}$

We would like to add our voice to the growing call for high quality research into the clinically challenging dilemma of diagnosing and managing coexistent COPD (or chronic bronchitis) with bronchiectasis. Although radiological evidence of bronchiectasis is present in a significant proportion of people with COPD, defining the dominant condition in cases of established or severe co-existing disease poses a challenge, as does determination of the ideal pharmacological and non-pharmacological management for this "combined" phenotype.

\section{Disclosure}

The authors have no conflicts of interest in this communication.

\section{References}

1. Ramos FL, Krahnke JS, Kim V. Clinical issues of mucus accumulation in COPD. Int J Chron Obstruct Pulmon Dis. 2014;9:139-150.

2. Osadnik CR, McDonald CF, Jones AP, Holland AE. Airway clearance techniques for chronic obstructive pulmonary disease. Cochrane Database Syst Rev. 2012;3:CD008328.

3. Osadnik CR, McDonald CF, Miller BR, et al. The effect of positive expiratory pressure (PEP) therapy on symptoms, quality of life and incidence of re-exacerbation in patients with acute exacerbations of chronic obstructive pulmonary disease: a multicentre, randomised controlled trial. Thorax. 2014;69(2):137-143.

4. Cross J, Elender F, Barton G, et al. A randomised controlled equivalence trial to determine the effectiveness and cost-utility of manual chest physiotherapy techniques in the management of exacerbations of chronic obstructive pulmonary disease (MATREX). Health Technology Assessment. 2010;14(23):1-147, iii-iv.

5. Jones PW, Agusti AG. Outcomes and markers in the assessment of chronic obstructive pulmonary disease. Eur Resp J. 2006;27(4): $822-832$.

6. van der Schans CP. Airway clearance: assessment of techniques. Paediatr Respir Rev. 2002;3(2):110-114.

\section{Publish your work in this journal}

The International Journal of COPD is an international, peer-reviewed journal of therapeutics and pharmacology focusing on concise rapid reporting of clinical studies and reviews in COPD. Special focus is given to the pathophysiological processes underlying the disease, intervention programs, patient focused education, and self management protocols.

\section{Dovepress}

This journal is indexed on PubMed Central, MedLine and CAS. The manuscript management system is completely online and includes a very quick and fair peer-review system, which is all easy to use. Visit $\mathrm{http}: / /$ www.dovepress.com/testimonials.php to read real quotes from published authors. 